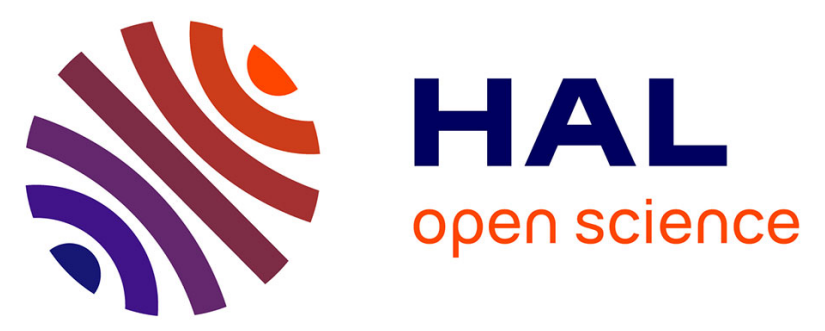

\title{
Light-Sensitive Alkoxyamines as Versatile Spatially- and Temporally-Controlled Precursors of Alkyl Radicals and Nitroxides
}

\author{
Marc Baron, Jason C. Morris, Siham Telitel, Jean-Louis Clément, Jacques \\ Lalevee, Fabrice Morlet-Savary, Arnaud Spangenberg, Jean-Pierre Malval, \\ Olivier Soppera, Didier Gigmes, et al.
}

\section{To cite this version:}

Marc Baron, Jason C. Morris, Siham Telitel, Jean-Louis Clément, Jacques Lalevee, et al.. LightSensitive Alkoxyamines as Versatile Spatially- and Temporally-Controlled Precursors of Alkyl Radicals and Nitroxides. Journal of the American Chemical Society, 2018, 140 (9), pp.3339-3344. 10.1021/jacs.7b12807 . hal-02091849

\section{HAL Id: hal-02091849 \\ https://hal-amu.archives-ouvertes.fr/hal-02091849}

Submitted on 3 Feb 2022

HAL is a multi-disciplinary open access archive for the deposit and dissemination of scientific research documents, whether they are published or not. The documents may come from teaching and research institutions in France or abroad, or from public or private research centers.
L'archive ouverte pluridisciplinaire HAL, est destinée au dépôt et à la diffusion de documents scientifiques de niveau recherche, publiés ou non, émanant des établissements d'enseignement et de recherche français ou étrangers, des laboratoires publics ou privés. 


\title{
Light-Sensitive Alkoxyamines as Versatile Spatially- and Temporally- Controlled Precursors of Alkyl Radicals and Nitroxides
}

\author{
Marc Baron, ${ }^{1}$ Jason C. Morris, ${ }^{1}$ Siham Telitel, ${ }^{2}$ Jean-Louis Clément, ${ }^{1}$ Jacques Lalevée, ${ }^{2}$ Fabrice Morlet- \\ Savary, ${ }^{2}$ Arnaud Spangenberg, ${ }^{2}$ Jean-Pierre Malval, ${ }^{2}$ Olivier Soppera, ${ }^{2}$ Didier Gigmes ${ }^{1}$ and Yohann \\ Guillaneuf ${ }^{1, *}$ \\ ${ }^{1}$ Aix Marseille Univ, CNRS, Institut de Chimie Radicalaire UMR 7273, Marseille, France. \\ ${ }^{2}$ Institut de Science des Matériaux de Mulhouse IS2M, UMR CNRS 7361, Université de Haute Alsace (UHA), Mulhouse, \\ France.
}

\begin{abstract}
The use of UV/visible light irradiation as a means to initiate organic syntheses is increasingly attractive due to the high spatial and temporal control conferred by photochemical processes. The aim of this work is thus to demonstrate that alkoxyamines bearing a chromophore on the alkyl moiety can provide a photo-protecting group for the sensitive nitroxide functionality, that is known to degrade through redox processes. The dissociation of various photosensitive alkoxyamines was studied from $223 \mathrm{~K}$ to $298 \mathrm{~K}$ under UV/visible irradiation, depending on the nature of the chromophore. In each case a rapid (typically in less than one hour) and near-quantitative dissociation was observed. As an illustration of the interest of this approach, a pyrene-based alkoxyamine was employed for the spatially controlled coupling of polymer chains onto Si wafers to produce micro-patterned surfaces.
\end{abstract}

\section{INTRODUCTION}

Nitroxide radicals are organic compounds containing an aminoxyl group, which is characterized by delocalization of an unpaired electron over a $\pi_{\mathrm{N}-\mathrm{O}}$ three-electron bond. This phenomenon is responsible for the remarkable thermodynamic stability of nitroxides, which has allowed numerous nitroxides to be isolated, stored and manipulated without special care. ${ }^{1,2}$ Nitroxides find application in numerous fields, from materials science to medicine. For example, the reversible scavenging properties of nitroxides versus alkyl radicals at high temperature allows for the controlled polymerization of various monomers, as well as for the preparation of complex nanostructured macromolecules. ${ }^{3}$ At lower temperatures, nitroxides, or the nitroxide precursors Hindered Amine Light Stabilizers (HALS), are widely used for the protection of polymeric materials from oxidative damage. ${ }^{4}$ The unpaired spin of nitroxides has also been exploited for the preparation of organic magnets, ${ }^{5}$ dynamic nuclear polarization agents for the enhancement of NMR signals, ${ }^{6}$ as well as for the preparation of dyesensitized solar cells ${ }^{7}$ and as active materials ${ }^{8}$ in organic batteries. Nitroxide are also widely used in biological systems ${ }^{9}$ as antioxidant, SOD mimics, MRI contrasting agent, ESR label, etc. Despite their numerous applications, the widespread application of nitroxides in these systems is hampered by the inherent sensitivity of the nitroxide functionality to reductive, oxidative and radical environments. Protection of the nitroxide moiety presents a promising methodology to avoid degradation. Few methodologies to protect the nitroxide moiety have been reported, amongst which, only the methoxyamine group was efficient. ${ }^{10}$ However, this technique lacks spatial control and the requisite use of $m \mathrm{CPBA}$ to release the nitroxide makes this technique unviable in vivo. Recently it has been reported that hydroxylamines could be produced by the photo-chemical deprotection of alkylated (2-nitrobenzyl) nitroxide derivatives. ${ }^{11}$ Moreover, alkoxyamines $\left(\mathrm{R}_{1} \mathrm{R}_{2} \mathrm{~N}-\mathrm{O}-\mathrm{R}_{3}\right)$ have also received considerable interest, since upon heating, these compounds release a stoichiometric ratio of alkyl and nitroxide radicals ${ }^{3,12}$ thus providing a promising protecting group for the nitroxide functionality. The decomposition of alkoxyamines is now well-understood and has been rationalized in several structure-reactivity relationships. ${ }^{13}$ Typically, the decomposition of alkoxyamines has been triggered by heat, although recently an increase/decrease in the rate of homolysis by protonation-quaternization of nitrogen atoms on the alkyl and nitroxide moieties have been reported. ${ }^{14}$ The use of UV/visible light irradiation as a means to initiate organic syntheses has become increasingly attractive due to the high spatial and temporal control of photochemically derived processes. ${ }^{15}$ We recently introduced alkoxyamines bearing a chromophore moiety as a new technique to control the polymerization of vinyl monomers under UV irradiation. ${ }^{16,17}$ Incorporation of a chromophore within either the alkyl or nitroxide moieties promoted homolytic dissociation of the NO-C bond under UV irradiation. ${ }^{18}$

Continuing in this approach, we sought to demonstrate that thermally-stable alkoxyamines bearing a chromophore on the alkyl moiety could provide a photo-protecting group for the sensitive nitroxide functionality, that is known to degrade through redox processes in organic and biological systems. Once this proof of concept is established, we illustrate this 
particular reactivity for performing surface patterning on silicon wafer (Figure 1).

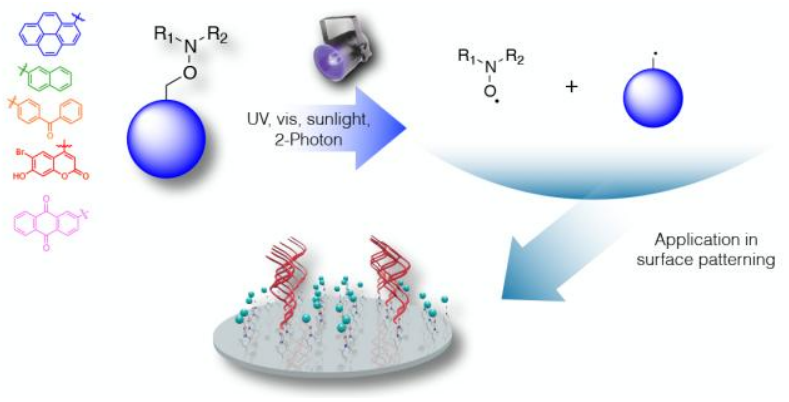

Figure 1. Photo-dissociation of alkoxyamine bearing a chromophore on the alkyl part. Application to surface patterning.

\section{RESULTS AND DISCUSSION}

Herein we first report the synthesis of alkoxyamines based on two of the most common nitroxides, namely 4-hydroxy2,2,6,6-tetramethylpiperidinyl-1-oxyl nitroxide (1) (OHTEMPO, Scheme 1) and $N$-tert-butyl- $N$-[1-diethylphosphono(2,2-dimethylpropyl)] nitroxide (2) (SG1 or DEPN, Scheme 1). The OH-TEMPO nitroxide (1) is well known for its high thermodynamic stability that has facilitated its use as an efficient radical scavenger. The incorporated hydroxyl group imparts water solubility, as well as the potential for functionalization of various substrates. ${ }^{3}$ Though the SG1 nitroxide (2) possesses a reduced thermodynamic stability relative to $\mathbf{1}$, the increased steric hindrance of $\mathbf{2}$, which was designed to enhance the dissociation rate constant of corresponding alkoxyamines, has widened the range of monomers that can be polymerized by NMP, as well as increased the scope of alkoxyamines in 1,2 radical addition reactions onto activated olefins. $^{3}$

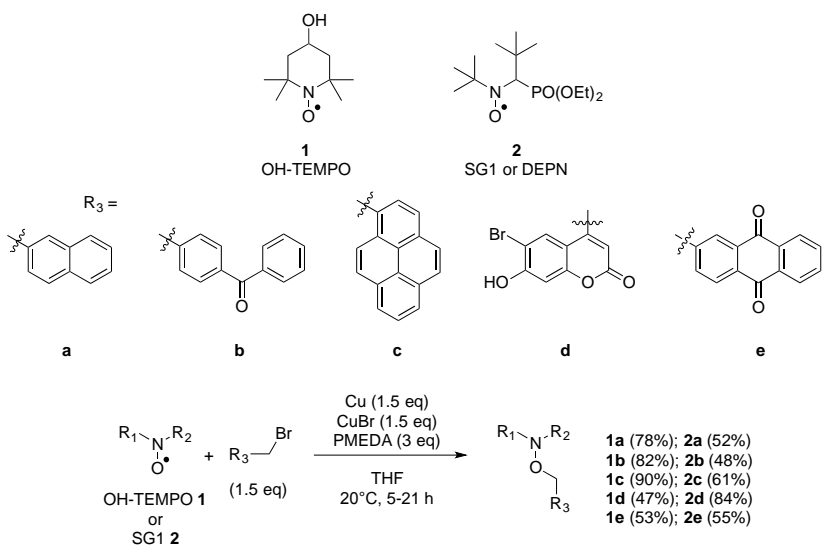

Scheme 1. Synthesis of photosensitive alkoxyamines.

The aim of this work was thus to prepare alkoxyamines that are relatively stable under thermal conditions, but that could be readily cleaved under UV or visible light irradiation. For that purpose we selected various chromophores that would release a primary stabilized alkyl (benzyl-like) radical upon dissociation. It is known that such alkoxyamines should possess an activation energy close to the model benzyl moiety, and thus the half-life of such molecules at $20{ }^{\circ} \mathrm{C}$ should be close to the one of model benzyl alkoxyamines that are 7700 and 127 years for TEMPO and SG1-based alkoxyamines respectively. ${ }^{3}$ The chromophores (naphthalene $\lambda_{\max }=320 \mathrm{~nm} \pi$ - $\pi^{*}$ transition, benzophenone $\lambda_{\max }=340 \mathrm{~nm} \mathrm{n}-\pi^{*}$ transition, pyrene $\lambda_{\max }=350 \mathrm{~nm} \pi-\pi^{*}$ transition, coumarin $\lambda_{\max }=385 \mathrm{~nm}$ charge transfer CT transition, anthraquinone $\lambda_{\text {max }}=390 \mathrm{~nm} n$ $\pi^{*}$ transition, Figure S1) were selected to have wide coverage of the UV and visible light spectrum, and thus to investigate if this methodology could be applied with a variety of irradiation sources (UV lamp, LED, sunlight). The alkoxyamines (Scheme 1) were prepared in good to moderate yields from their corresponding alkyl halides by the classic atom-transfer radical-addition (ATRA) method. ${ }^{19}$ Thermal dissociation of the investigated alkoxyamines were assessed by Electron Spin Resonance (ESR), using oxygen as the alkyl radical scavenger. ${ }^{20}$ The activation energies and half-lives at $20{ }^{\circ} \mathrm{C}$ are reported in Table S1. The extrapolated half-lives at $20{ }^{\circ} \mathrm{C}$ of the investigated alkoxyamines ranged from 250 days to 660 years. The reduced half-lives of the investigated alkoxyamines, relative to the model benzyl derivatives, is likely due to increased stabilization (for compounds a and c) and increased polarity (for compounds d) as explained by Marque and coworkers. ${ }^{13}$

ESR was employed to investigate the photo-dissociation efficiency of $\mathbf{2 c}$, to determine whether dissociation occurred via homolytic dissociation of the C-O bond to produce both an alkyl radical and a nitroxide. Indeed, a recent study ${ }^{11}$ reported the preparation of an alkylated nitroxide by reaction of the corresponding hydroxylaminate onto 2-nitrobenzyl bromide as a photo-protecting group. However, following irradiation hydroxylamine was reportedly produced, requiring further oxidation to obtain the corresponding nitroxide. A requirement for performing clean radical reactions is the establishment of the persistent radical effect (PRE). ${ }^{3,12}$ The PRE has most notably been applied to polymer science ${ }^{3}$ but also in organic chemistry, ${ }^{3}$ where clean radical additions onto various olefins, cyclizations, or cascade reactions have been performed in the absence of a metal catalyst. Thus the photo-dissociation of $\mathbf{2 c}$ was investigated in the presence, and absence, of $\mathrm{O}_{2}$ as the alkyl radical scavenger (Figure 2). In the presence of $\mathrm{O}_{2}$ decomposition of the alkoxyamine was complete after $1000 \mathrm{~s}$, yielding $95 \%$ of the desired nitroxide. In the absence of $\mathrm{O}_{2}$, the rate of photochemical decomposition was reduced. A plateau in the conversion of $\mathbf{2 c}$ to $\mathbf{2}$ was observed after a few hundred of seconds of irradiation, consistent with the establishment of a PRE. The steady state concentration of nitroxide was maintained over $9000 \mathrm{~s}$, when $\mathrm{O}_{2}$ was introduced within the ESR tube. Introduction of $\mathrm{O}_{2}$, as alkyl radical scavenger, restricted recombination of alkyl and nitroxide radicals, allowing for the complete decomposition of $\mathbf{2 c}$.

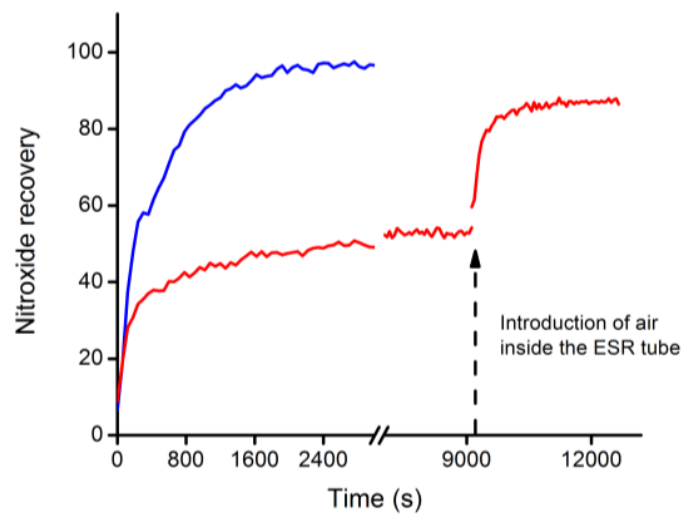

Figure 2. ESR monitoring of the decomposition of 2c using an LC8 Lamp with a UV filter $(365 \mathrm{~nm})$ at $10 \%$ of power $(1.2$ 
$\mathrm{mW} / \mathrm{cm}^{2}$ ). Blue line: decomposition under air. Red line: decomposition under an inert atmosphere, followed by introduction of air.

These results demonstrated that without oxygen, the lifetime of the alkoxyamine is extended, thus providing the opportunity for application of the investigated alkoxyamines to clean radical reactions under UV irradiation.

Photo-dissociation of the investigated alkoxyamines was examined from $223 \mathrm{~K}$ to $298 \mathrm{~K}$ under UV or visible light irradiation, depending on the nature of the chromophore. The results are gathered in Figure 3, where the formation of nitroxide versus time was followed by ESR and compared to a standard of TEMPO. In each case, a rapid and nearquantitative dissociation was observed, typically in less than one hour of UV or visible light irradiation. Alkoxyamines derived from the same nitroxide moiety displayed similar rates of decomposition (Figure 3a), indicating that the mechanism of photo-dissociation is different to thermally induced alkoxyamine bond homolysis, which is governed by the bond dissociation energy (BDE) of the NO-C group.

Moreover, for the same chromophore, the photodissociation of OH-TEMPO and SG1 based alkoxyamines was also similar (Figure 3a). The large differences in the activation energies of OH-TEMPO and SG1 based alkoxyamines (Table

a)

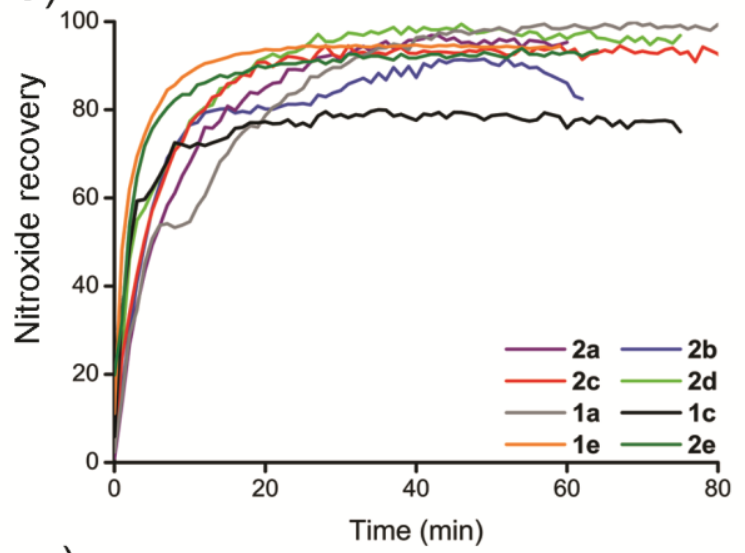

c)

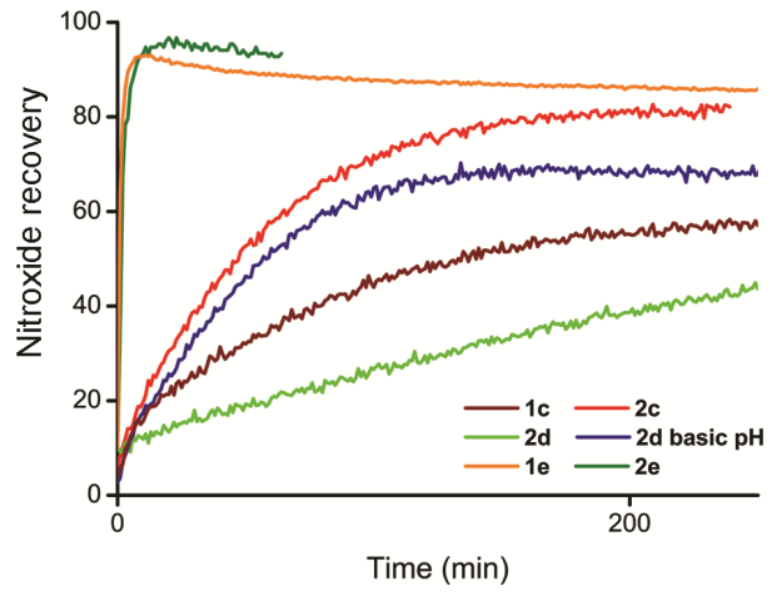

S1) suggests that the dissociation of such alkoxyamines should vary significantly, however, as the photo-dissociation $\mathrm{OH}$ TEMPO and SG1 based alkoxyamines were similar for a given chromophore, this may provide further evidence for the dissimilar mechanism of dissociation between thermally and photochemically induced dissociations. As expected, the rate of dissociation was linearly dependent on the lamp intensity, with, for example, complete decomposition of $\mathbf{2 c}$ occurring in $10 \mathrm{~min}$ at $20 \%$ of lamp intensity, which was increased to 2 hours at $1 \%$ of lamp intensity (Figure 3b). These results demonstrate that the release of both the alkyl radical and the nitroxide could be temporally tuned by varying the intensity of the lamp. In the case of alkoxyamines bearing a chromophore with an absorbance in the visible light range, $i$. $e$. pyrene, coumarin and anthraquinone moieties, photo-dissociation of alkoxyamines also proceeded under visible light irradiation, albeit that the kinetics of dissociation were reduced compared to UV irradiation. It has to be noted that the rate of dissociation under visible light irradiation is dependent on the nitroxide moiety (decomposition of $\mathbf{2 c}>\mathbf{1 c}$ ) and follows the classic thermodynamic stability (Bond Dissociation Energy BDE of 1c $>2 c)$. b)

d)
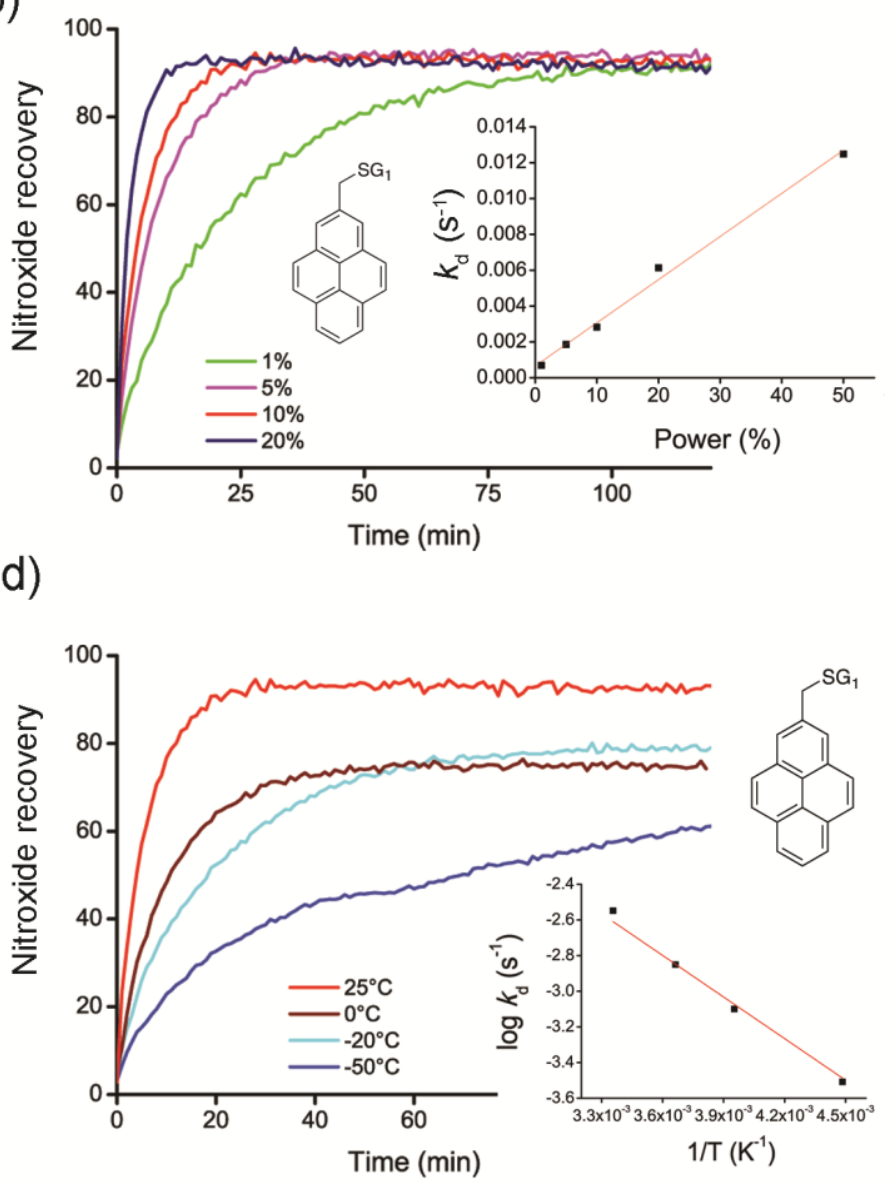

Figure 3. a) Influence of the alkoxyamine structure on the release of the nitroxide under UV irradiation (LC8 Lamp UV filter (365 nm) 10 $\%$ power $\left(1.2 \mathrm{~mW} / \mathrm{cm}^{2}\right)$ for alkoxyamines $\mathbf{2 b}, \mathbf{1 c}, \mathbf{1 e}, \mathbf{2 c}, \mathbf{2 d}, \mathbf{2 e}$; LC8 Lamp $1 \%$ power for alkoxyamines 1a, 2a) followed by ESR. b) Influence of the lamp power on the release of the nitroxide under UV irradiation (LC8 Lamp UV filter (365 nm), alkoxyamine 2c). c) Influence of the alkoxyamine structure on the release of the nitroxide under visible light irradiation (LC8 vis, $400-800 \mathrm{~nm}), 700 \mathrm{~mW} / \mathrm{cm}^{2}$ ). 
d) Influence of temperature on the release of the nitroxide under UV irradiation (LC8 Lamp UV filter (365 nm) $10 \%$ power, alkoxyamine 2c).

Concerning 2d, under basic conditions, the phenolic proton was abstracted, causing bathochromic and hyperchromic shifts in the absorbance (see SI), due to the formation of a charge transfer transition. Concerning the anthraquinone derivatives (1e and 2e), the rates of dissociation under UV and visible light irradiation were found to be similar, each requiring less than 20 min for complete dissociation. These results led us to envision softer irradiation conditions to investigate the decomposition 1e and 2e. UV-LED flexible strips (405 nm, Fig. S2) and direct sunlight were each employed as irradiation sources, with both providing similar rates of decomposition (less than $20 \mathrm{~min}$ ). It has to be noted that in solution, alkoxyamine 1e decomposes rapidly under ambient light. However, storage of the solid product on a bench for six months did not lead to any degradation of the alkoxyamine, revealing a remarkable photochemical stability in the solid state (see Figure S3). The influence of temperature on the rate of photo-dissociation of 2c was examined from $223 \mathrm{~K}$ to 298 $\mathrm{K}$. At each of the investigated temperatures dissociation of $\mathbf{2 c}$ was observed, however, it was found that the $k_{\mathrm{d}}$ value decreased slightly with decreasing temperature, following a pseudo Arrhenius law $\left(\log k_{\mathrm{d}}=3.67 \times \mathrm{e}^{-17800 / \mathrm{RT}}\right)$, ), indicating that the reaction may be better described as 'photo-induced' rather than a pure 'photo-chemical' process. Compared to the thermal $k_{\mathrm{d}}$ value at $0{ }^{\circ} \mathrm{C}$, the photochemical $k_{\mathrm{d}}$ is increased by a factor $2 \times 10^{6}$. Although it should be noted that due to an increase in the cage effect, with decreasing temperature, as well as the concomitant reduction in the concentration of dissolved $\mathrm{O}_{2}$, recombination of alkyl and nitroxide radicals is enhanced, impeding the complete conversion of $\mathbf{2 c}$ to $\mathbf{2}$.

To illustrate the potential of light sensitive alkoxyamines to induce temporal control over the photo-dissociation process, an on-off experiment was performed with alkoxyamine 1e. The results presented in Figure S4 demonstrate that following an increase in the nitroxide recovery under UV irradiation, cessation of UV irradiation results in an immediate pause of the nitroxide recovery, which remains constant in the absence of UV irradiation. Upon reapplication of UV irradiation, the nitroxide recovery immediately increases, further demonstrating the high degree of temporal control over the photodissociation process. A scale-up experiment was also performed using the alkoxyamine 1e. $75 \mathrm{~mL}$ of a $10^{-3} \mathrm{M}$ solution was irradiated with the LED apparatus for $1 \mathrm{~h}$. After 2 hours of irradiation the nitroxide recovery was determined to be $>95 \%$ by ESR. The TEMPOL nitroxide was subsequently isolated in quantitative yield using with a straightforward procedure (see ESI for details).

The near-quantitative release of nitroxides at ambient temperature could potentially find biological application, for the spatially controlled release of the sensitive nitroxide functionality within the body. However, the limited tissue penetration of UV irradiation represents a major problem for practical biological application. Taking into account the optical window for deep tissue penetration (600 to $900 \mathrm{~nm}$ ), the non-linear optical process, two-photon absorption (2PA), presents an ideal means to release the nitroxide within the body. To be biologically relevant, 2PA of photosensitive alkoxyamines must facilitate efficient photo-dissociation, with a $2 \mathrm{PA}$ action cross section $\left(\delta_{\mathrm{u}}\right.$, the product of the two-photon absorbance cross section $\delta_{\mathrm{a}}$ and the uncaging quantum yield $\Phi$ ) greater than $0.1 \mathrm{GM}^{21}$ The bromo-coumarin chromophore (d) was selected for this purpose, as it has previously been utilized as a 2PA antenna for the rapid release of carboxylates and amines following the photolysis of corresponding esters and carbamates. ${ }^{22}$ The $2 \mathrm{PA}$ spectrum of the basic form of $\mathbf{d}$ has previously been measured in the $690-900 \mathrm{~nm}$ range by means of two-photon excited fluorescence. ${ }^{23}$ This coumarin derivative is highly emissive, with a fluorescence quantum yield $\left(\Phi_{\text {fluo }}\right)$ of 0.70 in acetonitrile. Figure 4 depicts the one- (1PA) and two- (2PA) photon absorption spectra of the basic form of the alkoxyamine 2d. The 2PA bands are plotted against half the excitation wavelength to provide a direct comparison to the linear absorption spectra. According to our spectral resolution, the 2PA spectrum consists of a single broad band that correlates well with the 1PA band. The maximum 2PA crosssection $(\delta)$ is approximately $13 \mathrm{GM}$ at $780 \mathrm{~nm}$, which leads to a 2PA action cross-section $\left(\delta_{\mathrm{u}}=\delta_{\mathrm{a}} \cdot \Phi_{\text {fluo }}\right)$ of ca. $9.1 \mathrm{GM}$. This result is highly promising as it presents the opportunity for spatial control over the release of the nitroxide within biological tissues. To obtain direct evidence for dissociation of the alkoxyamine under 2PA irradiation, a concentrated solution $\left(10^{-3} \mathrm{M}\right)$ of $1 \mathbf{d}$ in tert-butyl benzene was irradiated at 690 and $780 \mathrm{~nm}$ respectively. After prolonged irradiation due to the very small irradiation volume $(1 \mathrm{fL})$, an increase of the nitroxide signal was observed by ESR, confirming dissociation of 1d under 2PA conditions (see ESI for details).

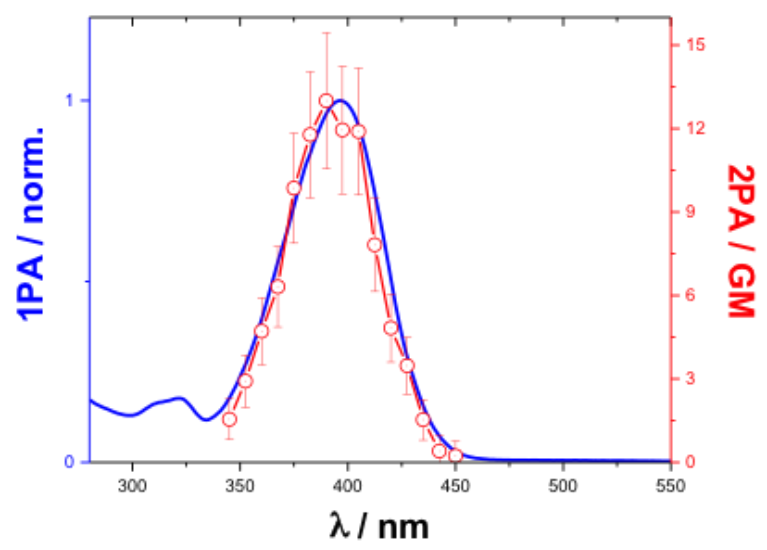

Figure 4. 1PA (full line) and 2PA (circles) absorbance spectra of 2d (solvent: ACN with $5 \times 10^{-4} \mathrm{M}$ of tetramethylguanidine).

Having established the photo-dissociation efficiency of the investigated alkoxyamines under UV and visible light irradiation, we sought to apply this reactivity to the coupling of polymeric macro-radicals onto silicon wafers for the preparation of micro-pattern surfaces. Spatially controlled functionalization of surfaces is currently widely investigated for biomaterial applications, micro/nano-fabrication, etc. ${ }^{24,25}$ In recent years, several methods for light-induced formation of reactive groups on surfaces have been developed. Functional groups such as cyclooctynes, nitrile imines, oximes and o-naphthoquinone methides have been utilized for the highly efficient ligation of an appropriate reaction partner. ${ }^{26-32}$ These methodologies are particularly efficient, but require specific end-group functionalities for each reaction partner. 
As the efficient combination of alkyl and nitroxide radicals could be viewed as a clean "click" reaction, ${ }^{33}$ capable of coupling a range of radical substrates to a nitroxide, we investigated a silane derivative of $\mathbf{1 c}$ (Figure 5), which was covalently attached to a silicon wafer using classic procedures. ${ }^{34}$ Upon successful silanization (as demonstrated by X-ray photoelectron spectroscopy (XPS, see Fig. S2) and by the change of the surface contact angle (see Fig S3)), spatially controlled deprotection of the nitroxide functionality on the silicon wafer was achieved through irradiation (365 nm Oriel lamp irradiation for 5 mins) of a shadow mask. The patterned wafer was then grafted with polymer chains through the coupling of in situ generated macro-radicals with surface-bound nitroxides (Figure 5).

As a proof of concept, we prepared by NMP, polystyrene functionalized by the SG1 nitroxide $\left(M_{\mathrm{n}}=4,900 \mathrm{~g} \cdot \mathrm{mol}^{-1}, Ð=\right.$ 1.2), which was then heated at $100{ }^{\circ} \mathrm{C}$ in anisole for two hours in the presence of the silicon wafer. We have previously demonstrated that nitroxide exchange occurs between PS-SG1 chains and TEMPO due to the marked difference of their bond dissociation energies. ${ }^{35}$ To ensure that polystyrene chains were covalently bound to the surface, extensive washing of the surface with toluene combined with ultrasound were performed.

Analysis of the surface by AFM confirmed efficient grafting of polymer chains. Similar grafting was obtained with a copolymer of styrene/chloromethyl styrene, which was further modified by reaction with Rose Bengal ${ }^{36}$ to covalently bind a chromophore to the polymer chains. After grafting, the fluorescent patterned material was analyzed by confocal microscopy (Figure 5). These experiments could be further extended to a variety of alkyl macro-radicals, generated through various methodologies such as; atom transfer radical addition/polymerization, or the decomposition of photoinitiators that absorb at wavelengths exceeding the spectral window of the photosensitive alkoxyamine employed, etc. Photosensitive alkoxyamines are thus a universal platform for the preparation of a wide range of patterns from a diverse array of precursors.

\section{CONCLUSION}

In this work, we showed that photosensitive alkoxyamine bearing a chromophore on the alkyl moiety and having a benzyl type structure undergo a fast and efficient dissociation under UV and/or visible light whatever the temperature. In addition two-photon irradiation could be used to produce the nitroxide using bromo-hydroxy coumarin as a chromophore. The first application of these compounds was to prepare micro-patterned surfaces. Besides this application, the spatially and temporally controlled release of alkyl and nitroxide radicals from the irradiation of light-sensitive alkoxyamines could find other interesting applications that are currently under investigation in our group in biology or in organic chemistry. a)

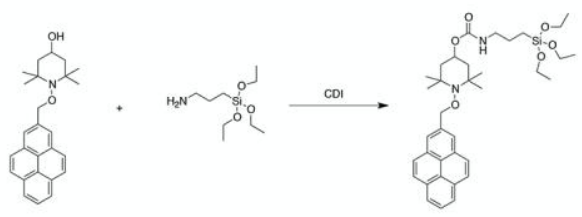

c)

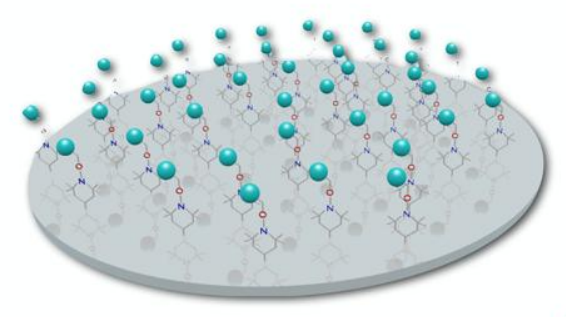

I)

II)

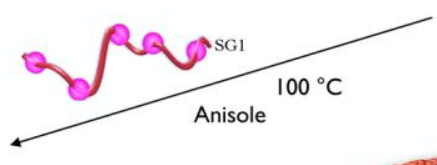

b)

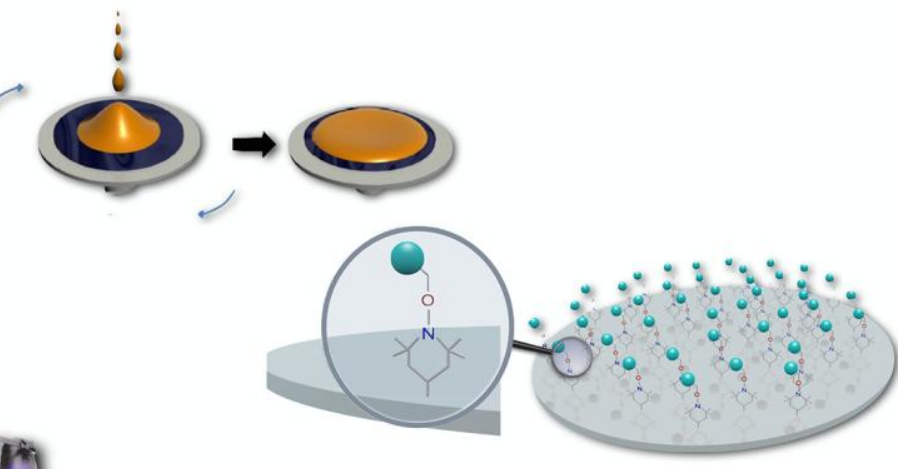

)
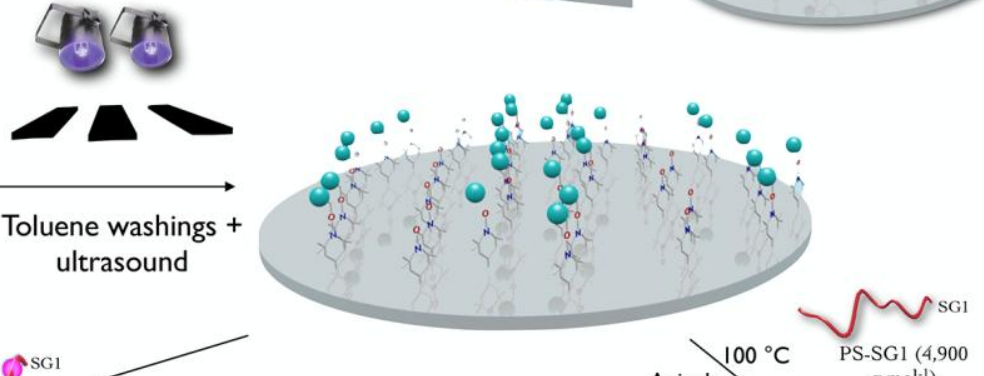
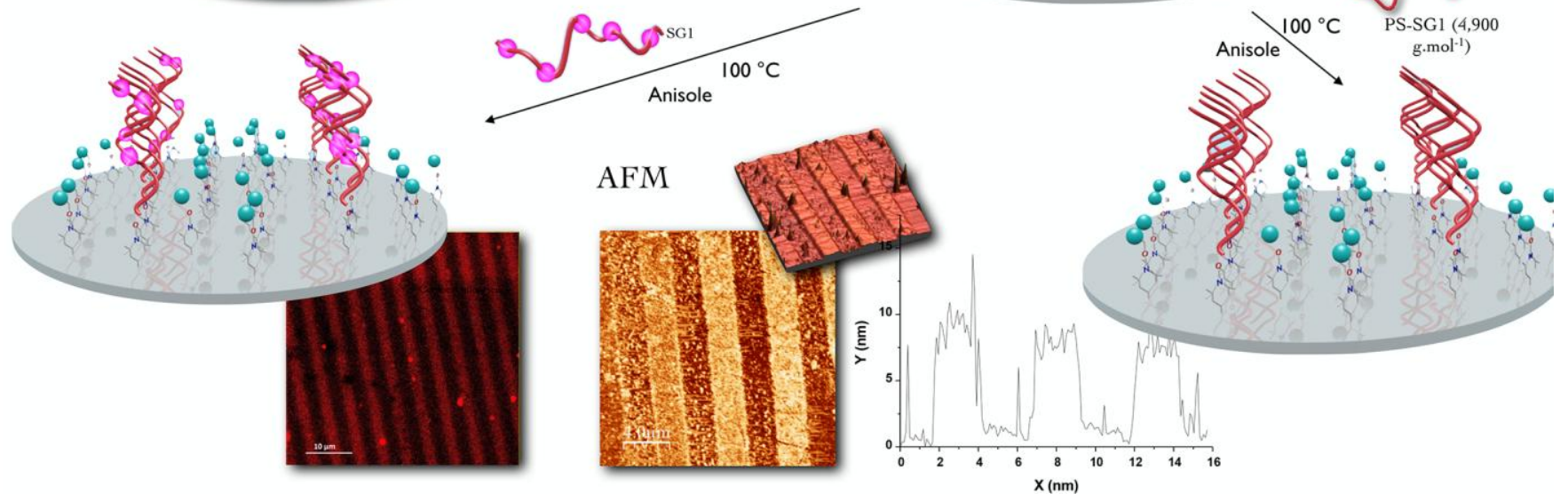
Figure 5. a) Synthesis of the silane derivative of 1c b) Preparation of the coated silicon wafer by silanization. c) Preparation of micropattern surfaces by nitroxide radical exchange method using either a PS-SG1 or a Rose Bengal-functionalized PS-SG1.

\section{ASSOCIATED CONTENT}

\section{Supporting Information}

The Supporting Information is available free of charge on the ACS Publications website. UV, ${ }^{1} \mathrm{H}$ NMR and ${ }^{13} \mathrm{C}$ NMR spectra of the photosensitive alkoxyamines. On-Off experiment, storage stability experiments, XPS and Contact Angle of the modified silicon wafer.

\section{AUTHOR INFORMATION}

\section{Corresponding Author}

*yohann.guillaneuf@univ-amu.fr

\section{ACKNOWLEDGMENT}

(The authors thank French Agence Nationale pour la Recherche (ANR) for funding (project IMPACT, ANR2011-BS08-016) and thank the Carnot MICA for funding the 3Dfabsurf project. Arkema is warmly acknowledged for kindly providing the SG1 nitroxide.

\section{REFERENCES}

(1) Aurich, H. In Nitrones, Nitronates and nitroxides; Breuer, E., Aurich, H., Nielsen, A., Eds.; John Wiley and sons: 1989.

(2) Karoui, H.; Le Moigne, F.; Ouari, O.; Tordo, P. In Stable Radicals: Fundamentals and Applied Aspects of Odd-Electron Compounds; Hicks, R. G., Ed.; John Wiley \& Sons, Ltd: Chichester, UK. , 2010.

(3) Nicolas, J.; Guillaneuf, Y.; Lefay, C.; Bertin, D.; Gigmes, D.; Charleux, B. Prog. Polym. Sci. 2013, 38, 63.

(4) Gryn'ova, G.; Ingold, K. U.; Coote, M. L. J. Am. Chem. Soc. 2012, 134, 12979.

(5) Barone, V.; Bencini, A.; diMatteo, A. J. Am. Chem. Soc. 1997, 119, 10831.

(6) Hu, K. N.; Yu, H. H.; Swager, T. M.; Griffin, R. G. J. Am. Chem. Soc. 2004, 126, 10844.

(7) Kato, F.; Kikuchi, A.; Okuyama, T.; Oyaizu, K.; Nishide, H. Angew. Chem., Int. Ed. Engl. 2012, 51, 10177.

(8) Nishide, H.; Oyaizu, K. Science 2008, 319, 737.

(9) Soule, B. P.; Hyodo, F.; Matsumoto, K.-i.; Simone, N. L.; Cook, J. A.; Krishna, M. C.; Mitchell, J. B. Free Radic. Biol. Med. 2007, 42, 1632 .

(10) Chalmers, B. A.; Morris, J. C.; Fairfull-Smith, K. E.; Grainger, R. S.; Bottle, S. E. Chem. Commun. 2013, 49, 10382.

(11) Seven, I.; Weinrich, T.; Gränz, M.; Grünewald, C.; Bruß, S.; Krstic, I.; Prisner, T. F.; Heckel, A.; Göbel Eur. J. Org. Chem. 2014, 4037.

(12) Studer, A.; Schulte, T. Chem. Rec. 2005, 5, 27.

(13) Bertin, D.; Gigmes, D.; Marque, S. R. A.; Tordo, P. Macromolecules 2005, 38, 2638.

(14) Audran, G.; Bremond, P.; Marque, S. R. A. Chem. Commun. 2014, 50, 9606.

(15) Chatani, S.; Kloxin, C. J.; Bowman, C. N. Polym. Chem. 2014, 5, 2187.
(16) Guillaneuf, Y.; Versace, D.-L.; Bertin, D.; Lalevee, J.; Gigmes, D.; Fouassier, J.-P. Macromol. Rapid Commun. 2010, 31, 1909.

(17) Guillaneuf, Y.; Bertin, D.; Gigmes, D.; Versace, D.-L.; Lalevee, J.; Fouassier, J.-P. Macromolecules 2010, 43, 2204.

(18) Versace, D.-L.; Guillaneuf, Y.; Bertin, D.; Fouassier, J. P.; Lalevee, J.; Gigmes, D. Org. Biomol. Chem. 2011, 9, 2892.

(19) Bertin, D.; Gigmes, D.; Le Mercier, C.; Marque, S. R. A.; Tordo, P. J. Org. Chem. 2004, 69, 4925.

(20) Marque, S.; Le Mercier, C.; Tordo, P.; Fischer, H. Macromolecules 2000, 33, 4403.

(21) Williams, R. M.; Piston, D. W.; Webb, W. W. Faseb J. 1994, $8,804$.

(22) Furuta, T.; Wang, S.; Dantzker, J. L.; Dore, T. M.; Bybee, W. J.; Callaway, E. M.; Denk, W.; Tsien, R. Y. Proc. Natl. Acad. Sci. USA 1999, 96, 1193.

(23) Xu, C.; Webb, W. W. J. Opt. Soc. Am. B Opt. Phys 1996, 13,481 .

(24) Cui, J.; San Miguel, V.; del Campo, A. Macromol. Rapid Commun. 2013, 34, 310.

(25) Delaittre, G.; Greiner, A. M.; Pauloehrl, T.; Bastmeyer, M.; Barner-Kowollik, C. Soft Matter 2012, 8, 7323.

(26) Kaupp, M.; Quick, A. S.; Rodriguez-Emmenegger, C.; Welle, A.; Trouillet, V.; Pop-Georgievski, O.; Wegener, M.; BarnerKowollik, C. Adv. Func. Mater. 2014, 24, 5649.

(27) Pauloehrl, T.; Welle, A.; Oehlenschlaeger, K. K.; BarnerKowollik, C. Chem. Sci. 2013, 4, 3503.

(28) Oehlenschlaeger, K. K.; Mueller, J. O.; Heine, N. B.; Glassner, M.; Guimard, N. K.; Delaittre, G.; Schmidt, F. G.; BarnerKowollik, C. Angew. Chem., Int. Ed. Engl. 2013, 52, 762.

(29) Glassner, M.; Oehlenschlaeger, K. K.; Welle, A.; Bruns, M.; Barner-Kowollik, C. Chem. Commun. 2013, 49, 633.

(30) Pauloehrl, T.; Delaittre, G.; Bruns, M.; Meissler, M.; Boerner, H. G.; Bastmeyer, M.; Barner-Kowollik, C. Angew. Chem., Int. Ed. Engl. 2012, 51, 9181.

(31) Pauloehrl, T.; Delaittre, G.; Winkler, V.; Welle, A.; Bruns, M.; Boerner, H. G.; Greiner, A. M.; Bastmeyer, M.; Barner-Kowollik, C. Angew. Chem., Int. Ed. Engl. 2012, 51, 1071.

(32) Gruendling, T.; Oehlenschlaeger, K. K.; Frick, E.; Glassner, M.; Schmid, C.; Barner-Kowollik, C. Macromol. Rapid Commun. 2011, 32, 807 .

(33) Barner-Kowollik, C.; Du Prez, F. E.; Espeel, P.; Hawker, C. J.; Junkers, T.; Schlaad, H.; Van Camp, W. Angew. Chem., Int. Ed. Engl. 2011, 50, 60.

(34) Flink, S.; van Veggel, F.; Reinhoudt, D. N. J. Phys. Org. Chem. 2001, 14, 407.

(35) Guillaneuf, Y.; Dufils, P. E.; Autissier, L.; Rollet, M.; Gigmes, D.; Bertin, D. Macromolecules 2010, 43, 91.

(36) Pessoni, L.; Lacombe, S.; Billon, L.; Brown, R.; Save, M. Langmuir 2013, 29, 10264. 
Graphic entry for the Table of Contents (TOC)

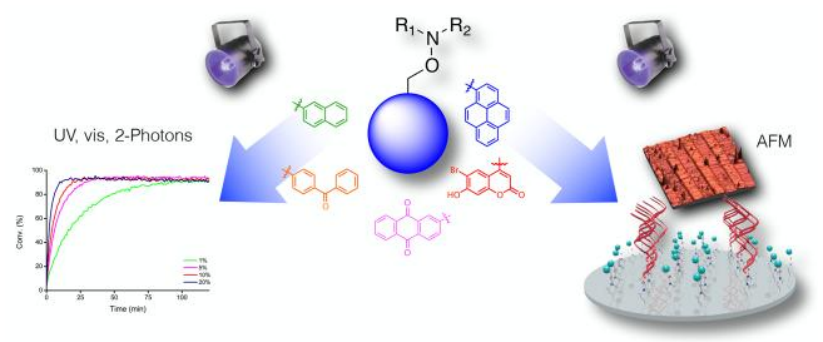

